\title{
Chronic Social Stress Inhibits Cell Proliferation in the Adult Medial Prefrontal Cortex: Hemispheric Asymmetry and Reversal by Fluoxetine Treatment
}

\author{
Boldizsár Czéh*,',2, Jeanine IH Müller-Keuker', Rafal Rygula', Nashat Abumaria', Christoph Hiemke ${ }^{3}$, \\ Enrico Domenici ${ }^{4}$ and Eberhard Fuchs ${ }^{1,2,5}$ \\ 'Clinical Neurobiology Laboratory, German Primate Center, Göttingen, Germany; ${ }^{2}$ DFG Research Center for the Molecular Physiology of the Brain, \\ Göttingen, Germany; ${ }^{3}$ Department of Psychiatry, University of Mainz, Mainz, Germany; ${ }^{4}$ Molecular Psychiatry, GSK Medicines Research Center, \\ Verona, Italy; ${ }^{5}$ Department of Neurology, Medical School, University of Göttingen, Göttingen, Germany
}

Profound neuroplastic changes have been demonstrated in various limbic structures after chronic stress exposure and antidepressant treatment in animal models of mood disorders. Here, we examined in rats the effect of chronic social stress and concomitant antidepressant treatment on cell proliferation in the medial prefrontal cortex (mPFC). We also examined possible hemispheric differences. Animals were subjected to 5 weeks of daily social defeat by an aggressive conspecific and received concomitant, daily, oral fluoxetine $(10 \mathrm{mg} / \mathrm{kg})$ during the last 4 weeks. Bromodeoxyuridine (BrdU) labeling and quantitative stereological techniques were used to evaluate the treatment effects on proliferation and survival of newborn cells in limbic structures such as the mPFC and the hippocampal dentate gyrus, in comparison with nonlimbic structures such as the primary motor cortex and the subventricular zone. Phenotypic analysis showed that neurogenesis dominated the dentate gyrus, whereas in the mPFC most newborn cells were glia, with smaller numbers of endothelial cells. Chronic stress significantly suppressed cytogenesis in the mPFC and neurogenesis in the dentate gyrus, but had minor effect in nonlimbic structures. Fluoxetine treatment counteracted the inhibitory effect of stress. Hemispheric comparison revealed that the rate of cytogenesis was significantly higher in the left mPFC of control animals, whereas stress inverted this asymmetry, yielding a significantly higher incidence of newborn cells in the right mPFC. Fluoxetine treatment abolished hemispheric asymmetry in both control and stressed animals. These pronounced changes in gliogenesis after chronic stress exposure may relate to the abnormalities of glial cell numbers reported in the frontolimbic areas of depressed patients.

Neuropsychopharmacology (2007) 32, |490-1503; doi:I0. I038/sj.npp. I 30 I275; published online I3 December 2006

Keywords: neurogenesis; stereology; cell number; glia; NG2; hippocampus

\section{INTRODUCTION}

Repeated stressful experiences have a profound impact on neural plasticity in various brain areas, especially in limbic structures such as the hippocampal formation, prefrontal cortex (PFC), and amygdala (McEwen, 2000; Vyas et al, 2002; Radley and Morrison, 2005). Probably, the most thoroughly investigated anatomical structure is the hippocampal formation, where numerous studies demonstrated that chronic stress exposure results in suppressed adult neurogenesis whereas mature principal neurons retract their dendritic tree and receive reduced number of synaptic

* Correspondence: Dr B Czéh, Clinical Neurobiology Laboratory, German Primate Center, Kellnerweg 4, D-37077 Göttingen, Germany, Tel: + 49551385 | 134, Fax: + 4955 I 3851 307,

E-mail: bczeh@cnl-dpz.de

Received 28 June 2006; revised 3 October 2006; accepted 16 October 2006 contacts (McEwen, 2000; Radley and Morrison, 2005). Recent studies demonstrate that chronic stress alters dendritic morphology not only in the hippocampus, but also in the medial PFC (Cook and Wellman, 2004; Radley et al, 2005). Parallel to these findings, a growing number of studies demonstrate that many of these stress-induced cellular changes can be reversed by antidepressant treatment (D'Sa and Duman, 2002; Dranovsky and Hen, 2006). It has been argued that these observations are likely to have human relevance as stressful life events are among the most potent factors known to trigger or induce major depressive episodes (Kendler et al, 1999). Thus, these findings contributed to the formulation of a novel concept that structural alterations including suppressed dentate neurogenesis may contribute to the pathogenesis of depression (Manji et al, 2001; Duman, 2004).

It has recently been reported that antidepressant treatment with fluoxetine or electroconvulsive seizure modulates cell proliferation not only in the dentate gyrus, but also in 
the medial PFC (mPFC) in adult rats (Kodama et al, 2004; Madsen et al, 2005). Unlike the hippocampal studies, the effects of antidepressant treatment on cytogenesis in the PFC have been investigated only in healthy animals (Kodama et al, 2004; Madsen et al, 2005). This approach is in contrast to clinical practice in which treatment is restricted to sufferers of affective disorders, and antidepressant medication or electroconvulsive stimulation in nondepressed individuals almost certainly does not produce the same neural changes as when these treatments are applied to depressed patients. In the present study, we applied the chronic social defeat paradigm in rats, which is regarded as an animal model of depression (Rygula et al, 2005, 2006a, b), to investigate the effect of chronic stress exposure and concomitant fluoxetine treatment on cell proliferation and neurogenesis in limbic structures, such as the hippocampal formation and PFC. To determine whether these interventions have a region-specific effect, we also analyzed other, nonlimbic brain areas such as the primary motor cortex and subventricular zone. As numerous animal studies demonstrate that the mPFC has hemispheric functional asymmetries (Sullivan and Gratton, 1999, 2002), we separately analyzed the two prefrontal hemispheres.

\section{MATERIALS AND METHODS}

\section{Animals, Experimental Procedures, and Fluoxetine Treatment}

Animals. Adult male Wistar rats, from Harlan-Winkelmann (Brochen, Germany) weighing $180-200 \mathrm{~g}$ at the time of arrival, were housed individually in type III macrolon cages, with rat chow and water available ad libitum. The colony room was maintained at a temperature of $21 \pm 1^{\circ} \mathrm{C}$ and on a reversed 12:12 h light:dark cycle (lights on at 2200). Lister Hooded male rats, weighing 300-350 g (HarlanWinkelmann) were used as residents. These animals were pair-housed with age-matched sterilized females in plastic cages $(60 \times 40 \times 40 \mathrm{~cm}=1 \times \mathrm{w} \times \mathrm{h})$ located in a separate room. Housing conditions were the same as for the Wistar rats. All experimental manipulations were conducted during the dark phase (activity period) under a dim red light. Animal experiments were conducted in accordance with the European Communities' Council Directive of November 24, 1986 (86/EEC), and were approved by the Government of Lower Saxony, Germany. The minimum number of animals required to obtain consistent data was used.

Experimental design, bromodeoxyuridine injection, and drug treatment. As shown in Figure 1a, two experiments were carried out. In Experiment I all animals received a single intraperitoneal (i.p.) injection of 5-bromo-2'-deoxyuridine (BrdU; $200 \mathrm{mg} / \mathrm{kg}$; Sigma; in saline) on the last experimental day (day 41 ) and were perfused $24 \mathrm{~h}$ later. The short survival time following BrdU injection allowed us to determine the effect of different manipulations on the proliferation rate of progenitor cells. The animals in Experiment I are called the 'proliferation group' throughout this article. Experiment II evaluated the effects of various interventions on the survival rate of the newborn cells. In these experiments, a second set of animals was injected with
BrdU $(2 \times 200 \mathrm{mg} / \mathrm{kg}$, i.p. $)$ on two consecutive days in the middle of the experimental procedure (days 21 and 22), and perfused at the end of the experiment, 20 days after the injection (Figure 1a). This set of animals is called the 'survival group'.

In Experiments I and II, animals were divided into four groups according to the stress and drug treatment protocol: Control, Control + Fluoxetine, Stress, and Stress + Fluoxetine (for animal numbers per group, see Figure 1a). According to the stress procedure and drug treatment, each experiment consisted of three phases and lasted for 6 weeks (42 days). During the first 7 days ('No stress') animals were handled and habituated to a daily oral vehicle administration (see below). The second experimental phase lasted 7 days, during which the animals of the Stress and the Stress + Fluoxetine group were submitted to daily social conflict (see below). The third experimental phase consisted of fluoxetine treatment for 4 weeks (28 days), during which animals remained in the daily social conflict situation. Animals of the Control + Fluoxetine and Stress + Fluoxetine groups received the compound $(10 \mathrm{mg} / \mathrm{kg}$ body weight/day) orally between 1500 and 1600 hours. The drug FluoxetineRatiopharm ${ }^{\circledR}(4 \mathrm{mg} / \mathrm{ml}$ oral solution; Ratiopharm $\mathrm{GmbH}$, Ulm, Germany) was administered via a bulb-headed cannula into the buccal cavity, and the animals were allowed to swallow the solution. Animals of the Control and Stress groups were treated with vehicle only. Animals received the drug orally because this is the most common route of antidepressant administration in psychiatric patients.

Chronic social defeat paradigm. The chronic social stress in these rats is based on the resident-intruder paradigm originally described by Miczek (1991) and Koolhaas et al (1997). Social defeat was induced as reported in Rygula et al (2005). The female resident rats were removed from the residents' cages before the social defeat procedure. Each experimental male Wistar rat was transferred from its home cage and introduced to a resident's cage. Within 1-3 min, the intruder was attacked and defeated by the resident, as indicated by freezing behavior and submissive posture. The intruder and resident were then immediately separated, and the intruder was kept in a small wire mesh compartment $(25 \times 15 \times 15 \mathrm{~cm})$ within the resident's cage for $1 \mathrm{~h}$. Hence, the intruder (experimental animal) was protected from direct physical contact, but remained in olfactory, visual and auditory contact with the resident. Intruders were returned to their home cages after this procedure. Animals from the stress groups were subjected daily to social defeat for 5 weeks. To avoid individual differences in the defeat intensity, each day the intruders were confronted with a different resident in a Latin square design. Control animals were handled daily throughout the entire experiment. Handling consisted of picking up each rat, transferring it to the experimental room and returning it to its home cage.

\section{Perfusion and Brain Tissue Preparation}

On day 42 , animals were deeply anesthetized with a mixture of xylazine $(50 \mathrm{mg} / \mathrm{ml})$ and ketamine $(10 \mathrm{mg} / \mathrm{ml})$, and blood was collected from the heart for further analysis of plasma 


\section{Experimental Groups}

\section{Experimental Procedures}

Experiment I: Proliferation

\begin{tabular}{|c|c|c|c|c|}
\hline & & & & . \\
\hline Control & No stress & No stress & No stress & $n=5$ \\
\hline Control + Fluoxetine & No stress & No stress & No stress + Fluoxetine & $n=6$ \\
\hline Stress & No stress & & & \\
\hline Stress + Fluoxetine & No stress & & Stress + Fluoxetine & $n=6$ \\
\hline
\end{tabular}

Experiment II: Survival

BrdU

day $21+22$

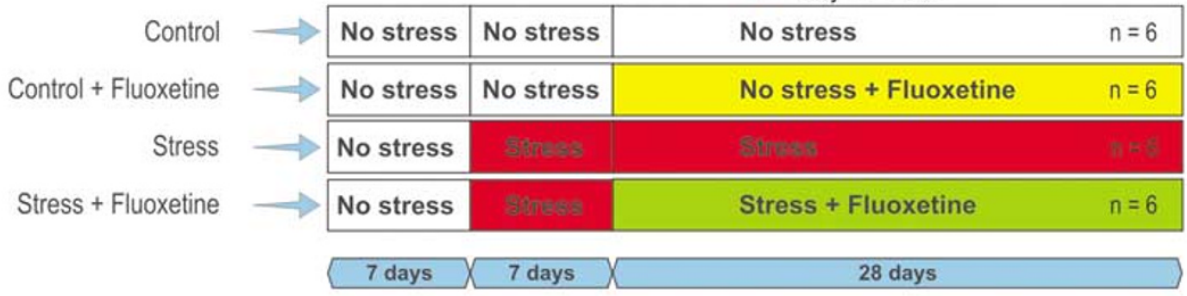

b

Investigated areas in the prefrontal cortex

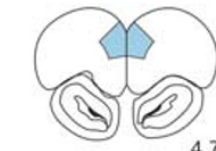

4.70 Bregma

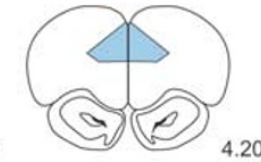

4.20
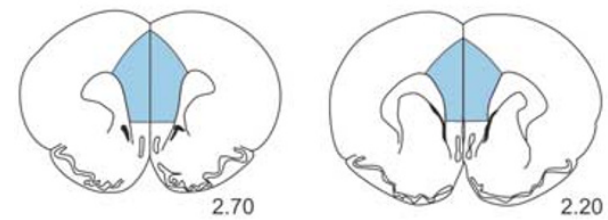

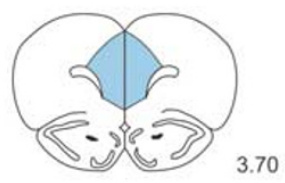

3.70
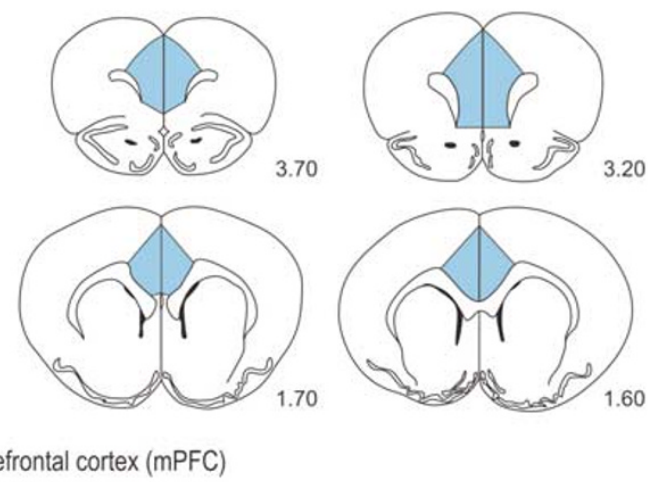

medial prefrontal cortex (mPFC)

c

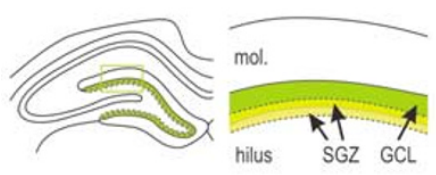

Dentate gyrus

\section{Reference areas}

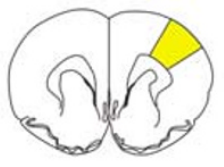

Primary motor cortex

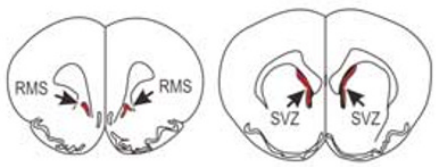

Rostral migratory stream (RMS)/ Subventricular zone (SVZ)

Figure I (a) Experimental design, groups and the number of animals employed in the study. For details, see Materials and methods. (b) Stereological cell counting of BrdU-positive cells was carried out in the mPFC, in both hemispheres, separately. Regions of interest are displayed on a series of plates, modified from Paxinos and Watson (1986). (c) The number of BrdU-labeled cells was evaluated in three additional reference areas, such as the hippocampal dentate gyrus, primary motor cortex and subventricular zone/rostral migratory stream, to determine whether or not the effect of stress and/or fluoxetine treatment on cytogenesis is specific to limbic areas. GCL: granule cell layer; SGZ: subgranular zone; mol: stratum moleculare.

concentrations of fluoxetine and its pharmacologically active metabolite norfluoxetine. After blood sample collections, the animals were transcardially perfused with cold $0.9 \% \mathrm{NaCl}$ for $3 \mathrm{~min}$, followed by cold $4 \%$ paraformaldehyde in $0.1 \mathrm{M}$ phosphate buffer (PB), $\mathrm{pH} 7.2$ for $12 \mathrm{~min}$. To prevent the development of postperfusion artifacts, the heads were postfixed in fresh fixative at $4{ }^{\circ} \mathrm{C}$. On the following day, the brains were gently removed and stored in $0.1 \mathrm{M}$ PB at $4^{\circ} \mathrm{C}$. For cryoprotection, the brains were immersed in $30 \%$ sucrose and $10 \%$ glycerol in $0.1 \mathrm{M} \mathrm{PB}$ at $4^{\circ} \mathrm{C}$. The brains were then dissected into blocks that contained the two hemispheres of the entire PFC (5.70 to $-0.40 \mathrm{~mm}$ Bregma; Paxinos and Watson, 1986) or the complete right hippocampal formation $(-0.40$ to $-7.80 \mathrm{~mm}$ Bregma; Paxinos and Watson, 1986), frozen on dry ice and stored at $-80^{\circ} \mathrm{C}$ before coronal serial sectioning on a Leica cryostat at a thickness of $50 \mu \mathrm{m}$. For the PFC, a small hole was made with a thin needle in the left hemisphere during the cutting procedure to differentiate the left and right hemispheres. 


\section{BrdU Immunocytochemistry}

All samples from each treatment group were processed in parallel to avoid nonspecific effects of the staining procedure. Every sixth section was mounted on Superfrost ${ }^{\mathbb{R}}$ slides (Menzel-Gläser, Braunschweig, Germany), and coded to ensure objectivity before processing for immunocytochemistry; the code was revealed only after all analyses were completed. The sections were washed in $0.1 \mathrm{M}$ phosphatebuffered saline (PBS) and then the DNA was denaturized in $0.1 \mathrm{M}$ citric acid at $\mathrm{pH} 6.0$ and $95^{\circ} \mathrm{C}$ for $20 \mathrm{~min}$. After treating with $1 \% \mathrm{H}_{2} \mathrm{O}_{2}$ in $\mathrm{PBS}$ for $20 \mathrm{~min}$, the sections were washed in PBS and $0.1 \mathrm{M}$ Tris, and the membranes were permeabilized with $0.1 \%$ trypsin in $0.1 \mathrm{M}$ Tris for $10 \mathrm{~min}$. After washing in Tris and PBS, the sections underwent acidification in $2 \mathrm{~N} \mathrm{HCl}$ in PBS for 30 min. After washing in PBS, nonspecific binding was prevented by incubating the sections for $1 \mathrm{~h}$ in $5 \%$ normal goat serum (NGS; Vector Laboratories, Burlingame) in PBS containing $0.5 \%$ Triton $\mathrm{X}-100$. Subsequently, the sections were incubated for one night at $4{ }^{\circ} \mathrm{C}$ with 1:100 mouse anti-BrdU (DakoCytomation, Hamburg, Germany) in the incubation solution (1\% NGS, $0.5 \%$ Triton X-100 in PBS). After washing, the sections were incubated with biotinylated goat anti-mouse (Sigma, 1:200 in incubation solution) for $2 \mathrm{~h}$, thoroughly washed, incubated with horseradish peroxidase-conjugated streptavidin (DakoCytomation, 1:200 in incubation solution) for $90 \mathrm{~min}$ and washed again. BrdU-labeled cells were visualized in $0.025 \% 3,3^{\prime}$-diaminobenzidine and $0.01 \% \mathrm{H}_{2} \mathrm{O}_{2}$ in $\mathrm{PBS}$ for $5 \mathrm{~min}$. Sections were washed in PBS and counterstained with cresyl violet. After overnight drying at $37^{\circ} \mathrm{C}$, the sections were cleared in xylene and coverslipped with Eukitt.

\section{Phenotypic Analysis of the Newly Generated Cells}

BrdU double labeling for immunofluorescence. Before processing, the sections were coded, and the code was revealed only after all analyses were completed. Hippocampal sections were double labeled for BrdU and the neuronal marker NeuN, or BrdU and the glial marker GFAP. Sections from the PFC were double labeled for BrdU and the neuronal marker NeuN, or BrdU and the endothelial marker RECA-1 (Duijvestijn et al, 1992), or BrdU and NG2, a marker for synantocytes and oligodendrocyte precursor cells (Butt et al, 2002). In pilot studies, we tested several other cell markers, but the above-mentioned antibodies identified majority of the BrdU-positive cells in the dentate gyrus and mPFC.

All washings and incubations for double labeling were performed on free-floating sections in $0.1 \mathrm{M}$ Tris at $\mathrm{pH}$ 7.5. First, sections were washed and then treated with $1 \% \mathrm{H}_{2} \mathrm{O}_{2}$ for 20 min. After washing, the sections for NeuN, GFAP and RECA-1 were incubated with $2 \mathrm{~N} \mathrm{HCl}$ for $1 \mathrm{~h}$ at room temperature and subsequently washed again. Sections were then blocked with $3 \%$ normal donkey serum (NDS; Sigma) and $0.5 \%$ Triton $\mathrm{X}-100$ for $1 \mathrm{~h}$ at room temperature. The antibody incubation solution consisted of $1 \%$ NDS and $0.5 \%$ Triton X-100. The sections were incubated for $48 \mathrm{~h}$ at $4{ }^{\circ} \mathrm{C}$ with one of the following primary antibodies for determining phenotypes. For hippocampal phenotypes, mouse anti-NeuN (1:1000, Chemicon, MAB377) or mouse
anti-GFAP (1:10 000, Sigma, G3893) was used. For the PFC phenotypes, mouse anti-NeuN (1:1000, Chemicon, MAB377), mouse anti-rat RECA-1 (1:1000, Serotec, MCA970) or mouse anti-NG2 (1:200, Chemicon, MAB5384) was used. After washing, Alexa Fluor ${ }^{\circledR} 594$ donkey anti-mouse (1:200, Invitrogen, Molecular Probes, Karlsruhe, Germany) was applied for $3 \mathrm{~h}$ at $4^{\circ} \mathrm{C}$. The sections were thoroughly washed. NG2 sections were treated with $4 \%$ PFA for $10 \mathrm{~min}$ at room temperature, washed, incubated with $2 \mathrm{~N} \mathrm{HCl}$ for $30 \mathrm{~min}$ at room temperature, and washed again. Then for double labeling of all phenotypic markers, the sections were incubated with fluorescein isothiocyanate-conjugated rat anti-BrdU (1:200, Genetex, GTX75736) for 2 days at $4^{\circ} \mathrm{C}$. After washing, the sections were mounted onto glass slides and dried at room temperature, quickly rehydrated in $0.1 \mathrm{M}$ Tris, and coverslipped with fluorescent mounting medium (DakoCytomation).

Phenotypic characterization of BrdU-labeled cells. Double labeling was examined with a confocal microscope (LSM 5 Pascal, Zeiss, Germany) with a $\times 63$ oil objective (NA 1.4, Plan-APOCHROMAT, Zeiss, Germany). BrdU-positive cells were first identified and then colocalized with NeuN or GFAP (dentate gyrus), and NeuN, RECA-1 or NG2 (PFC) was assessed. On average, $45 \mathrm{BrdU}$-labeled dentate cells and $83 \mathrm{BrdU}$-positive cells in the PFC were evaluated per animal.

\section{Quantification of BrdU-Labeled Cells}

A single examiner who was blind to the group identification of each animal performed the data collection. The code was not broken until the cell counting analyses were completed.

Prefrontal cortex. Initially, we separately analyzed the three subregions of the medial PFC (anterior cingulate (ACC), prelimbic (PL), and infralimbic (IL) cortices)), but because the outcome of such a detailed analysis would not be as conclusive as analysis of the combined data, we merged these three areas and presented the pooled data for the medial PFC (Figure 1b). Cell numbers were separately determined for the left and right hemispheres. A modified unbiased stereology protocol (Keuker et al, 2001) was used to determine the total number of BrdU-labeled cells. After randomly selecting a starting point, every sixth section between Bregma 4.70 and $1.60 \mathrm{~mm}$ (Paxinos and Watson, 1986) was analyzed, yielding an average of 10 sections per animal for quantification. First, the boundaries of the ACC, PL, and IL were demarcated for stereological analysis using a low-power magnification lens $(\times 2.5$, NA 0.08$)$. The total number $(N)$ of BrdU-positive cells was estimated with the optical diector following fractionator rules (Gundersen $\mathrm{et} \mathrm{al}$, 1988; West, 1999), and a semiautomated system (StereoInvestigator, version 4.04, Microbrightfield, Williston, VT). Video images of BrdU-positive cells were acquired with a $\times 40$ objective (NA 0.75 ) on a Zeiss III RS microscope (Carl Zeiss, Oberkochen, Germany) equipped with a CCD camera with its output presented on a high-resolution computer monitor, and a Ludl X-Y-Z motorized stage (Ludl Electronics Products, Hawthorn, NY). A BrdU-positive cell was counted only if it was within the disector area, did not intersect forbidden lines and came into focus as the optical plane moved through the height of the disector. After 
having counted all cells, fulfilling the criteria of sampling, the total number of cells was estimated as

$$
N_{\text {total }}=\Sigma Q^{-} \times 1 / s s f \times A(x, y \text { step }) / a(\text { frame }) \times t / h,
$$

where $\Sigma Q^{-}$is the number of counted BrdU-positive cells; ssf is the section sampling fraction (1/6); $A(x, y$ step) is the area associated with each $x, y$ movement (sampling area), which was $150 \times 150 \mu \mathrm{m}$; and $a$ (frame) is the area of the counting frame, which was $50 \times 50 \mu \mathrm{m}$. Proper optical disector rules require guard zones at both the upper and lower surfaces of the section, but here we applied the modified optical disector method in which we did not use guard zones. Thus, the height of the optical disector, $h$, equals the actual section thickness, $t$; hence, the thickness sampling fraction equals $1(t / h=1)$.

Dentate gyrus. The modified unbiased stereology protocol (Keuker et al, 2001) we used has been successful in quantifying BrdU labeling (Malberg et al, 2000; Czéh et al, 2001). Every sixth section throughout the dentate gyrus was examined, yielding a mean of 16 sections per animal. Stereological quantification requires determining the number of all BrdU-positive cells in a predefined fraction throughout the complete region of interest (Keuker et al, 2001). We used a section sampling fraction of $1 / 6$, and an area and a thickness sampling fraction of one. Cells were examined under $\times 400$ and $\times 1000$ magnification, omitting cells in the outermost focal planes. To obtain estimates of the total number of BrdU-labeled cells, we multiplied the number of counted cells in every sixth section by six. We estimated the total number of BrdU-labeled cells in the granule cell layer together with the subgranular zone, which is defined as a two-cell-body-wide zone along the border of the granule cell layer of the right hemisphere (Figure 1c).

Nonlimbic regions. In the primary motor cortex and the rostral migratory stream/subventricular zone, the density of BrdU-labeled cells was determined in four sections per animal between Bregma 2.70 and $1.60 \mathrm{~mm}$ (Paxinos and Watson, 1986) (Figure 1c). When analyzing the primary motor cortex, a sampling area was drawn in a way to include all cortical layers, indicated by a yellow area drawn in the motor cortex on Figure 1c. All BrdU-positive cells within this sampling area were counted using a $\times 40$ objective (NA 0.75). The sum of the BrdU-positive cells within this frame was divided by the surface area of the counting frame to get the density of the newborn cells. In case of the primary motor cortex, only the left hemisphere were analyzed. In the rostral migratory stream/subventricular zone, cells were counted in both hemispheres in a similar way, using a sampling area of $0.1 \times 0.1 \mathrm{~mm}$ square placed on the region of interest.

\section{Analysis of Fluoxetine and Norfluoxetine}

Fluoxetine and its pharmacologically active metabolite norfluoxetine were determined in blood plasma samples collected at the end of each experiment, as described in detail previously (Czéh et al, 2006). We used a highperformance liquid chromatography (HPLC) method with column switching and ultraviolet (UV) spectrophotometric detection at $210 \mathrm{~nm}$ as described for the antipsychotic drug, amisulpride (Sachse et al, 2003). There was a linear correlation between drug concentration and detector signal from 20 to at least $500 \mathrm{ng} / \mathrm{ml}$. Intra- and interassay reproducibility was below $10 \%$. The limit of quantification was $10 \mathrm{ng} / \mathrm{ml}$ for both fluoxetine and norfluoxetine.

\section{Body and Adrenal Weights}

Body weights were measured regularly, first at the end of the 'No stress' phase to assess the baseline, and subsequently at weekly intervals. Because increased adrenal weights are indicators of sustained stress exposure, these organs were removed from animals immediately after perfusion and then weighed. Data are expressed in organ weight in milligrams per gram of the average body weight measured in the preceding week.

\section{Statistical Analysis}

Results are expressed as group means \pm SEM. Treatment effects were assessed with two-way analysis of variance (ANOVA), followed by Student-Newman-Keuls post hoc analysis for further examination of group differences. Paired $t$-tests were used to evaluate interhemispheric differences.

\section{RESULTS}

\section{Changes of Body and Adrenal Weights as an Indicator of Stress Exposure}

Reduced body weight gain and enlarged adrenals are reliable indices for stress experience in rats (Muscat and Willner, 1992; Sapolsky et al, 2000). Because of the repeated social defeat, stressed rats gained less body weight than did the control rats after $2(p<0.05), 3(p<0.01), 4(p<0.01)$, and $5(p<0.01)$ weeks of social stress, as compared with controls (Figure 2a). Fluoxetine had no effect in control animals on body weight gain. Stressed animals treated with fluoxetine also gained less body weight compared with controls after $1(p<0.01), 2(p<0.001), 3(p<0.001), 4$ $(p<0.001)$, and $5 \quad(p<0.01)$ weeks of social stress (Figure 2a). Two-way ANOVA (treatment $\times$ time) showed significant effects for treatment $\left(\mathrm{F}_{(3,5)}=60.67, p<0.001\right)$, and the number of weeks of stress $\left(\mathrm{F}_{(3,5)}=132.37\right.$, $p<0.001)$. The reduction in weight gain was not due to reduced food and water intake.

Daily social defeat for 5 weeks resulted in increased adrenal weights in the stressed animals (Figure 2b), and analysis with two-way ANOVA (stress $\times$ drug) revealed a significant effect of stress on adrenal gland/body weight ratio at the time of autopsy $(p<0.001)$, but not of drug treatment $(p=0.6)$. The post hoc test showed that the adrenal gland/body weight ratio was significantly increased in Stress $(p<0.001)$ and Stress + Fluoxetine animals $(p<0.05)$ when compared with controls.

\section{Serum Concentrations of Fluoxetine and Norfluoxetine}

After four weeks of daily oral fluoxetine application $(10 \mathrm{mg} /$ $\mathrm{kg}$ ) and $24 \mathrm{~h}$ after the last application, we determined the concentrations of fluoxetine and its major metabolite norfluoxetine in the blood plasma. In the Control + Fluoxetine 

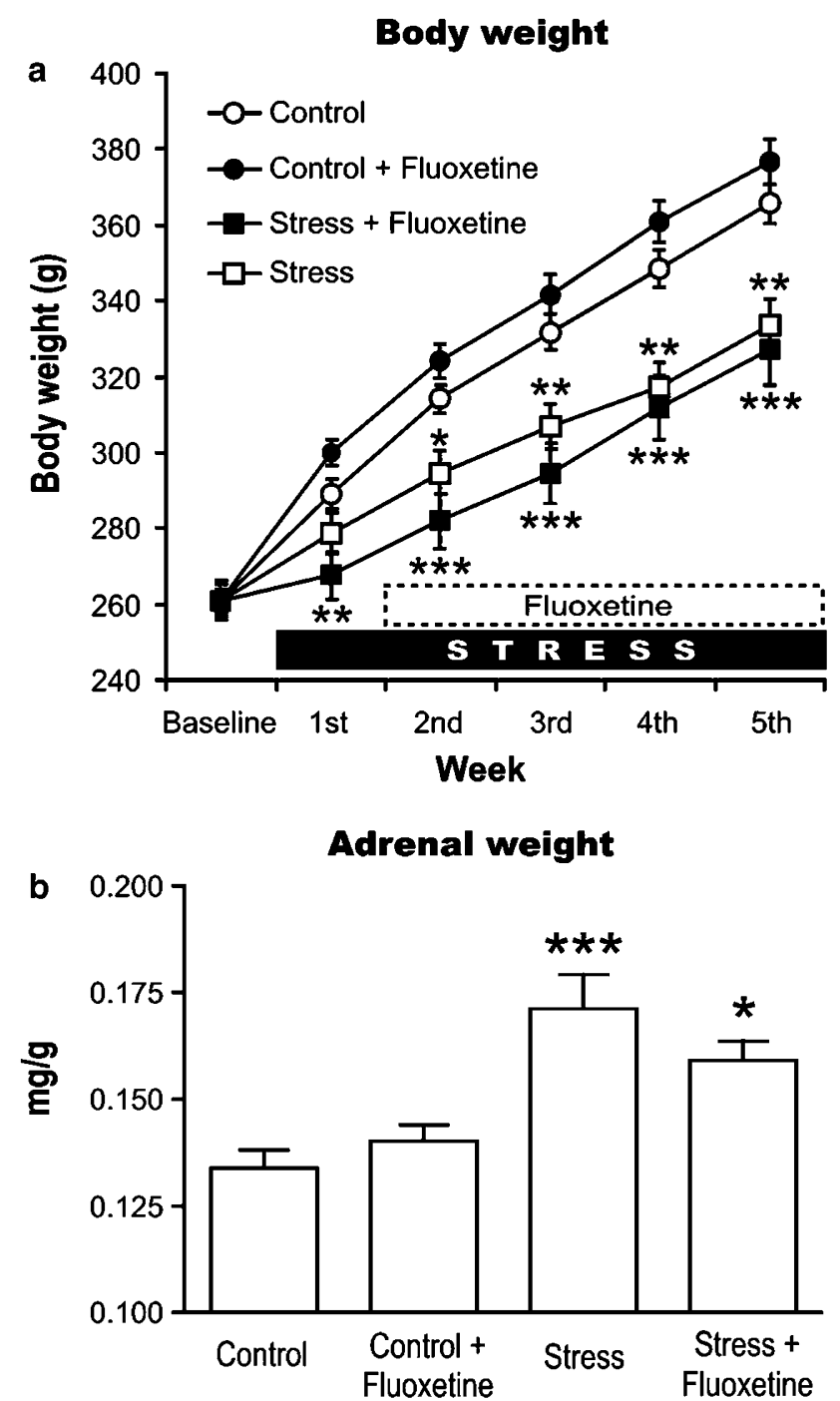

Figure 2 The physiological consequences of the repeated psychosocial stress were expressed in the significant changes in body weight gain (a) and relative adrenal weights (b). Because of repeated social defeat, stressed rats gained less weight, and their adrenals were significantly enlarged. Results are given as organ weight in $\mathrm{mg} / \mathrm{g}$ average body weight during the last experimental week (mean \pm SEM). Statistics: two-way ANOVA (a) treatment $\times$ weeks; (b) stress $\times$ drug) followed by Student-NewmanKeuls post hoc analysis. ${ }^{*} p<0.05$, *** $p<0.0$ I, **** $p<0.00$ I vs Control.

group, the parent compound fluoxetine was not detectable $(<10 \mathrm{ng} / \mathrm{ml})$. However, norfluoxetine was in the range of $139 \pm 21 \mathrm{ng} / \mathrm{ml}$. Analysis of blood samples from the Stress + Fluoxetine group revealed a similar picture with no detectable fluoxetine, but norfluoxetine in the range $134 \pm 21 \mathrm{ng} / \mathrm{ml}$. There was no significant difference between the Control+ Fluoxetine and Stress + Fluoxetine groups. The sum of plasma concentrations of fluoxetine and norfluoxetine was similar to those reported in human patients treated with therapeutically effective doses (Baumann et al, 2004).

\section{Chronic Stress Inhibits Neurogenesis in the Dentate} Gyrus: Reversal by Fluoxetine Treatment

Proliferation group. The generation of new neurons is the end product of a series of steps consisting of proliferation,

\section{Dentate gyrus \\ Proliferation group}

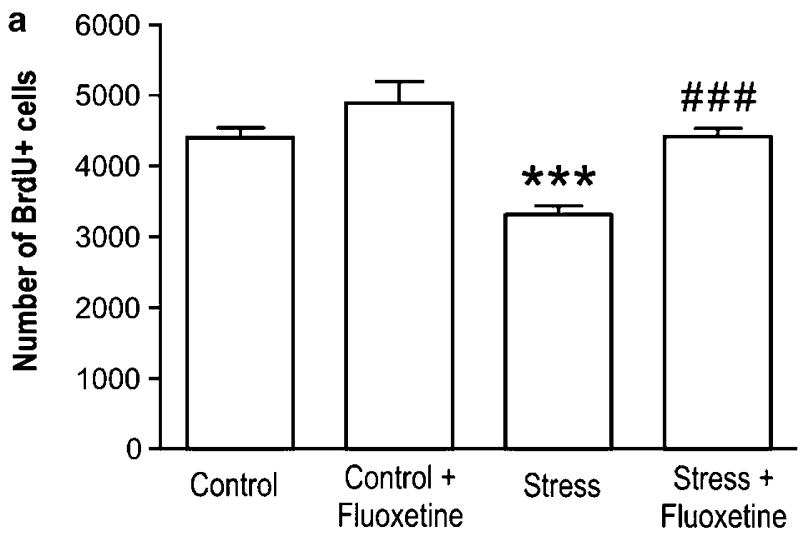

\section{Survival group}

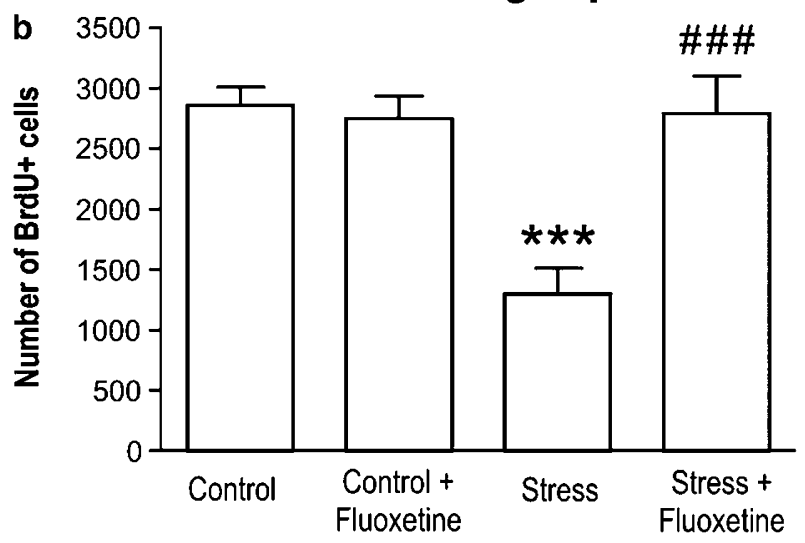

Figure 3 Effects of chronic psychosocial stress and concomitant fluoxetine treatment on cell proliferative activity (a) and survival of newborn cells (b) in the dentate gyrus. (a) Repeated social defeat (Stress) significantly suppressed cell proliferation, whereas fluoxetine treatment prevented the stress-induced effect. (b) The survival rate of the newborn cells was also significantly suppressed by chronic social stress, and this was also counteracted by fluoxetine treatment. Results are given as the total number of BrdU-positive cells per right dentate gyrus (mean \pm SEM). Statistics: two-way ANOVA (stress $x$ drug) followed by Student-Newman-Keuls post hoc analysis: ${ }^{* * * *} p<0.00$ I, vs Control; ${ }^{\# \#} p<0.00$ I, vs Stress.

survival, migration, differentiation, and establishment of functional connections with other neurons (Lledo et al, 2006). In animals killed $24 \mathrm{~h}$ after BrdU injection, the BrdUpositive cells in the dentate gyrus represents the number of newly generated cells (cell proliferation rate; Figure 3a). Histological analysis of the right dentate gyrus showed that chronic psychosocial stress resulted in a substantial reduction (by 25\%) in the number of BrdU-positive cells compared with unstressed Controls (Figure 3a). Two-way ANOVA (stress $\times$ drug) revealed a significant main effect of stress $\left(\mathrm{F}_{(3,19)}=18.41, p<0.001\right)$, and of drug treatment $\left(\mathrm{F}_{(3,19)}=19.24, p<0.001\right)$. Post hoc comparisons showed a significant difference between the Control and Stress groups $(q=5.83, p<0.001)$. Treatment of stressed animals with fluoxetine protected animals from the effects of stress, resulting in the complete preservation of BrdU-immunoreactive cells and a statistically significant difference 
between the Stress + Fluoxetine and Stress groups $(q=6.21$, $p<0.001)$. In contrast, no difference was found between the Stress + Fluoxetine and Control groups. Fluoxetine treatment alone in control animals had nonsignificant increase in cell proliferation (Figure 3a).

Survival group. The effects of stress or fluoxetine treatment on the survival of the newborn cells that were generated predominantly in the early part of the stress and drug exposure were detected by injecting animals with BrdU at the end of the first week of fluoxetine treatment (Figure 1a). The number of surviving BrdU-positive cells in the right dentate gyrus of each group is shown in Figure 3b. Two-way ANOVA (stress $\times$ drug) analysis revealed a significant main effect of stress $\left(\mathrm{F}_{(3,20)}=10.45, p<0.01\right)$, drug treatment $\left(\mathrm{F}_{(3,20)}=8.69, p<0.01\right)$, and for stress $\times$ drug interaction $\left(\mathrm{F}_{(3,20)}=11.55, p<0.01\right)$. Stress resulted in a $55 \%$ decrease in the number of BrdU-labeled cells and post hoc comparisons showed a significant difference between the Control and Stress groups $(q=6.63, p<0.001)$. Treatment of stressed animals with fluoxetine resulted in a significant increase in the number of BrdU-labeled cells $(q=6.34$, $p<0.001 v s$ Stress), but treatment with fluoxetine had no effect on the survival of newborn cells in control animals (Figure 3b).
Stress Inhibits Cell Proliferation and Survival in the mPFC: Reversal by Fluoxetine Treatment

Proliferation group. Chronic psychosocial stress inhibited cell proliferation both in the left $(-55 \%)$ and right hemisphere $(-32 \%)$ compared with unstressed Controls (Figure $4 \mathrm{a}$ and $\mathrm{b}$ ).

In the left hemisphere, two-way ANOVA (stress $\times$ drug) analysis revealed a significant major effect of stress $\left(\mathrm{F}_{(3,19)}=29.85, p<0.001\right)$, but not of drug treatment, and a significant stress $\times$ drug interaction $\left(\mathrm{F}_{(3,19)}=13.27\right.$, $p<0.01)$. Post hoc comparisons showed a significant difference between the Control and Stress groups $(q=8.89, p<0.001)$. Treatment of stressed animals with fluoxetine increased proliferative activity, resulting in a statistically significant difference between the Stress and Stress + Fluoxetine groups $(q=5.14, p<0.01)$. However, the Stress + Fluoxetine-treated animals still had a significantly lower number of BrdU-positive cells in their left mPFC compared with the Control group $(q=3.99, p<0.05)$.

In the right hemisphere, two-way ANOVA (stress $\times$ drug) analysis revealed a significant main effect of stress $\left(\mathrm{F}_{(3,19)}=9.47, p<0.01\right)$, and drug treatment $\left(\mathrm{F}_{(3,19)}=8.72\right.$, $p<0.01)$. Post hoc comparisons showed a significant difference between the Control and Stress groups $(q=3.77, p<0.05)$. Fluoxetine treatment of the stressed
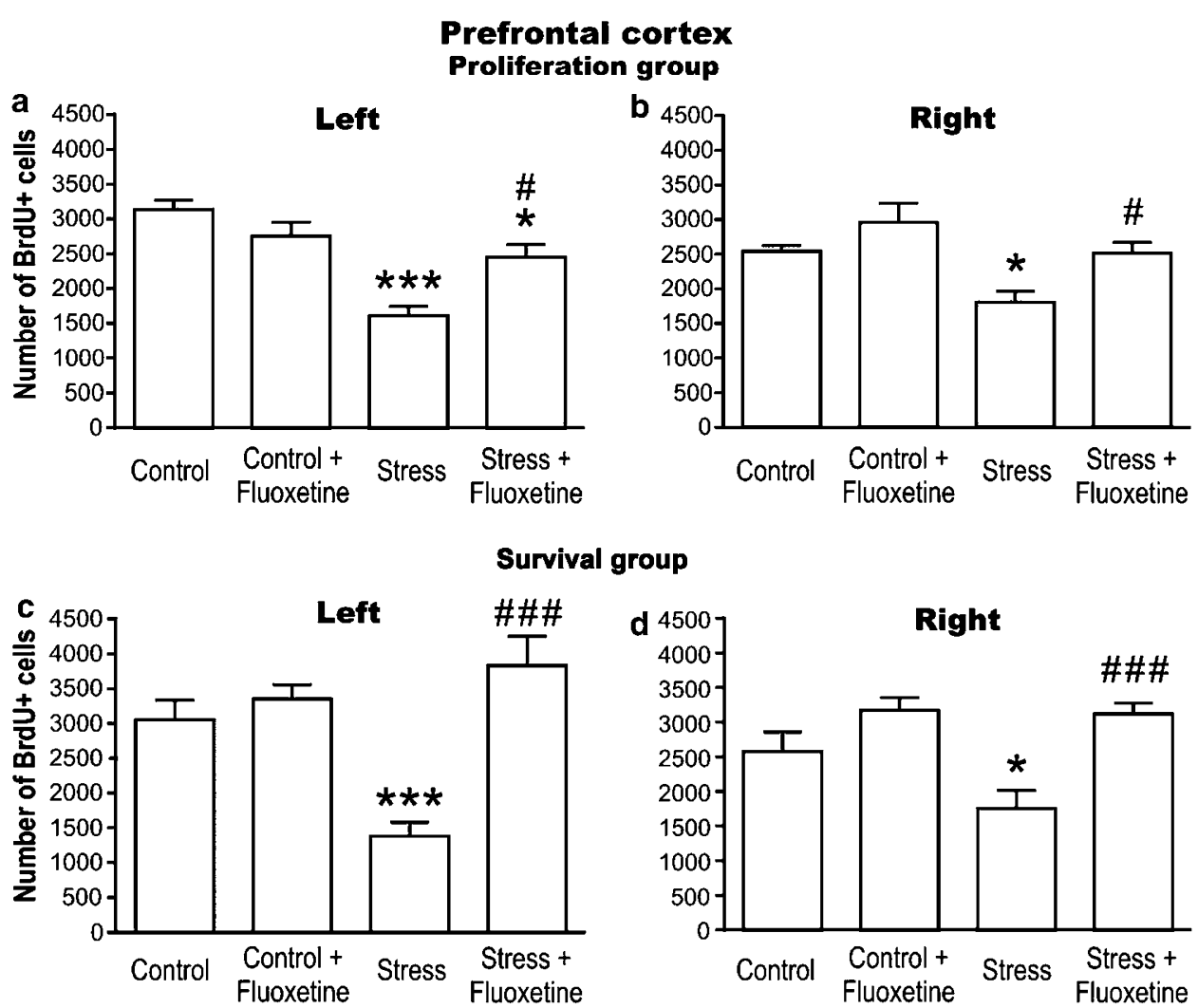

Figure 4 Effects of chronic social defeat and concomitant fluoxetine treatment on cell proliferative activity (a and b) and survival of newborn cells (c and d) in the mPFC. Chronic stress (Stress) significantly inhibited cell proliferation both in the left (a) and right hemispheres (b), whereas concomitant fluoxetine treatment counteracted the stress-induced effect. The survival rate of the newborn cells was also significantly suppressed by chronic stress in both hemispheres ( $c$ and $d$ ) and this was also blocked by fluoxetine treatment. The figures are the total estimated numbers of BrdU-positive cells in the three regions of the mPFC (anterior cingulate, prelimbic, and infralimbic cortices). Statistics: two-way ANOVA (stress $\times$ drug) followed by Student-NewmanKeuls post hoc analysis: ${ }^{*} p<0.05,{ }^{*} * * * 0.00$ I, vs Control; ${ }^{*} p<0.05,{ }^{\# \# \#} p<0.00$ I, vs Stress. 
animals increased proliferative activity, yielding a statistically significant difference between the Stress and Stress + Fluoxetine groups $(q=3.83, p<0.05)$, but no difference was found between the Stress + Fluoxetine group and controls. In control animals, fluoxetine treatment alone, slightly but not significantly, increased $(+16 \%)$ cell proliferation (Figure 4b).

Survival group. Chronic psychosocial stress suppressed the survival rate of the newly generated cells both in the left $(-49 \%)$ and right hemisphere $(-29 \%)$ relative to unstressed Controls (Figure $4 \mathrm{c}$ and $\mathrm{d}$ ).

In the left hemisphere, two-way ANOVA (stress $\times$ drug) analysis showed a significant main effect of stress $\left(\mathrm{F}_{(3,20)}=4.2, p=0.05\right)$, significant effects for drug treatment $\left(\mathrm{F}_{(3,20)}=22.62, \quad p<0.001\right)$, and stress $\times$ drug interaction $\left(\mathrm{F}_{(3,20)}=13.84, p<0.001\right)$. Post hoc comparisons showed a significant difference between the Control and Stress groups $(q=5.77, p<0.001)$. Treatment of stressed animals with fluoxetine increased the survival rate of the newborn cells, resulting in a statistically significant difference between the Stress and Stress + Fluoxetine groups $(q=8.47, p<0.001)$.

In the right hemisphere, two-way ANOVA (stress $\times$ drug) analysis revealed a significant main effect of drug treatment $\left(\mathrm{F}_{(3,20)}=19.26, p<0.001\right)$, and the effect of stress was close to the level of significance $\left(\mathrm{F}_{(3,20)}=3.79, p=0.06\right)$. Post hoc comparisons showed a significant difference between the
Control and Stress groups $(q=3.67, p<0.05)$. Fluoxetine treatment of the stressed animals increased the survival rate of the newly generated cells, yielding a statistically significant difference between the Stress and Stress + Fluoxetine groups $(q=6.11, p<0.001)$. In control animals, fluoxetine treatment alone slightly, but nonsignificantly increased the survival rate of the newborn cells by $23 \%$ (Figure 4d).

\section{Cytogenesis Reveals Intrinsic Hemispheric Asymmetry in the Medial PFC}

As shown in Figure 5, hemispheric differences were revealed when we compared the incidence of cytogenesis in the mPFC of nonmedicated animals. In control animals, both the proliferative activity and survival of newborn cells was higher in the left hemisphere compared with the right (proliferation group: paired $t$-test $t=6.11, p<0.01$; survival group: $t=5.91, p<0.01)$. Chronic psychosocial stress suppressed both the proliferative activity and survival of newborn cells to a greater extent in the left hemisphere. This resulted in a reversed asymmetry and a significantly higher incidence of cytogenesis in the right $\mathrm{mPFC}$ (proliferation group: $t=5.64, p<0.01$; survival group: $t=2.98, p<0.05$ ). In contrast to the nonmedicated animals, fluoxetine treatment abolished hemispheric asymmetry in both control and stressed animals (Figure 5).
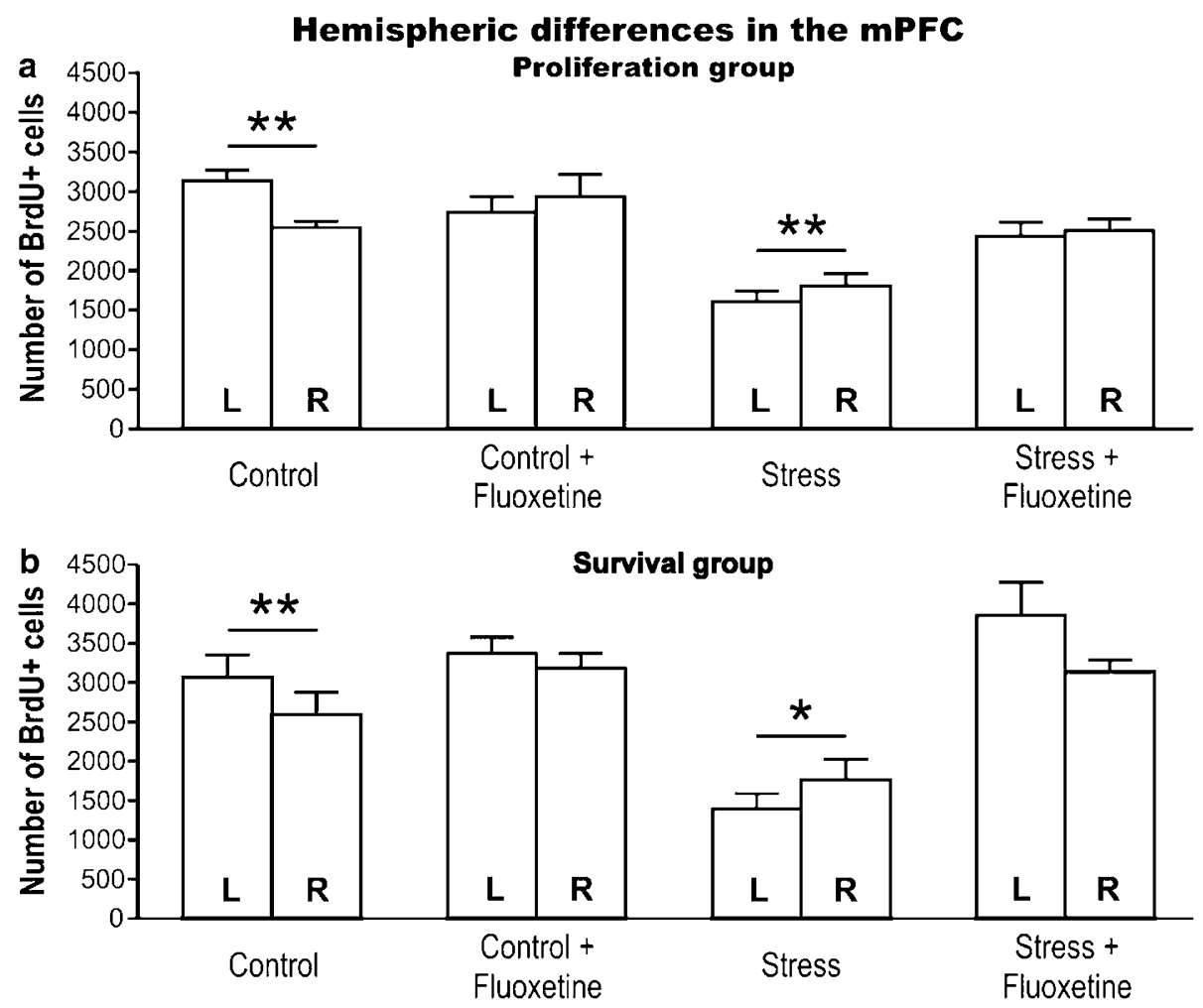

Figure 5 Cytogenesis in the mPFC showed intrinsic hemispheric asymmetry. In control animals, both the cell proliferative activity (a) and survival rate of newborn cells (b) was always higher in the left hemisphere, whereas chronic stress (Stress) reversed this asymmetry yielding a significantly smaller incidence of newborn cells in the left mPFC. Fluoxetine treatment abolished hemispheric asymmetry both in control and stressed animals. The figures are the total estimated number of the BrdU-positive cells in the three regions of the MPFC (anterior cingulate, prelimbic, and infralimbic cortices). Statistics: paired $t$-test ${ }^{*} p<0.05, * * * 0.0$ I. L: left; R: right. Data shown in this figure are identical to those in Figure 4; however, in the current figure data are presented in a way that facilitates the hemispheric comparison. 


\section{Phenotypic Analysis of the Newly Generated Cells}

Animals in the survival group were injected with BrdU 3 weeks before perfusion. During these 3 weeks, the BrdUlabeled newborn cells differentiated, which enabled us to carry out a phenotypic analysis of these cells. As shown in Figure 6, majority (70-77\%) of the newborn BrdU-positive cells in the dentate gyrus expressed the neuronal marker NeuN, whereas a minority (5-13\%) of the BrdU-labeled cells was double labeled with GFAP, an astroglia marker. These ratios were not significantly different between groups. We tried several other glial markers, but GFAP stained the largest population of BrdU-positive glial cells in the dentate gyrus, in agreement with earlier studies (eg, Malberg et al, 2000; Czéh et al, 2002).

We did not find any NeuN-positive BrdU-labeled cells in the prefrontal cortex; instead majority $(63-80 \%)$ of the BrdU-labeled cells coexpressed NG2, a marker for synantocytes and oligodendrocyte precursor cells. A minority (16$21 \%$ ) of the BrdU-positive cells was double labeled with RECA-1, a marker for rat endothelial cells, and these ratios were not significantly different between groups. We tested several other cell markers, but NG2 and RECA-1 identified the majority of BrdU-positive cells in the mPFC. The negative data obtained with the other cell markers are not reported here.
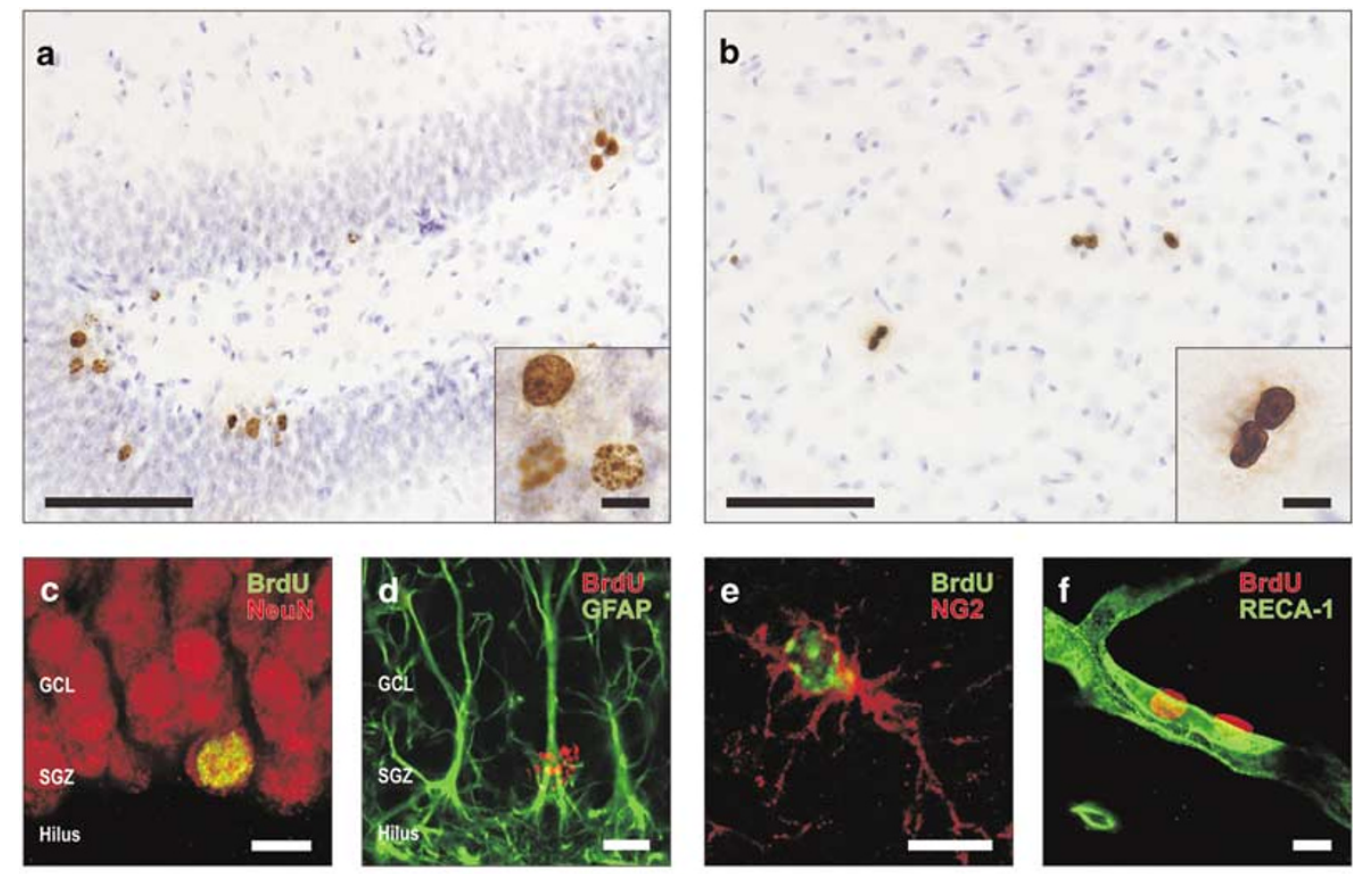

Phenotypic distribution of newborn cells in the dentate gyrus

Phenotypic distribution of newborn cells in the prefrontal cortex
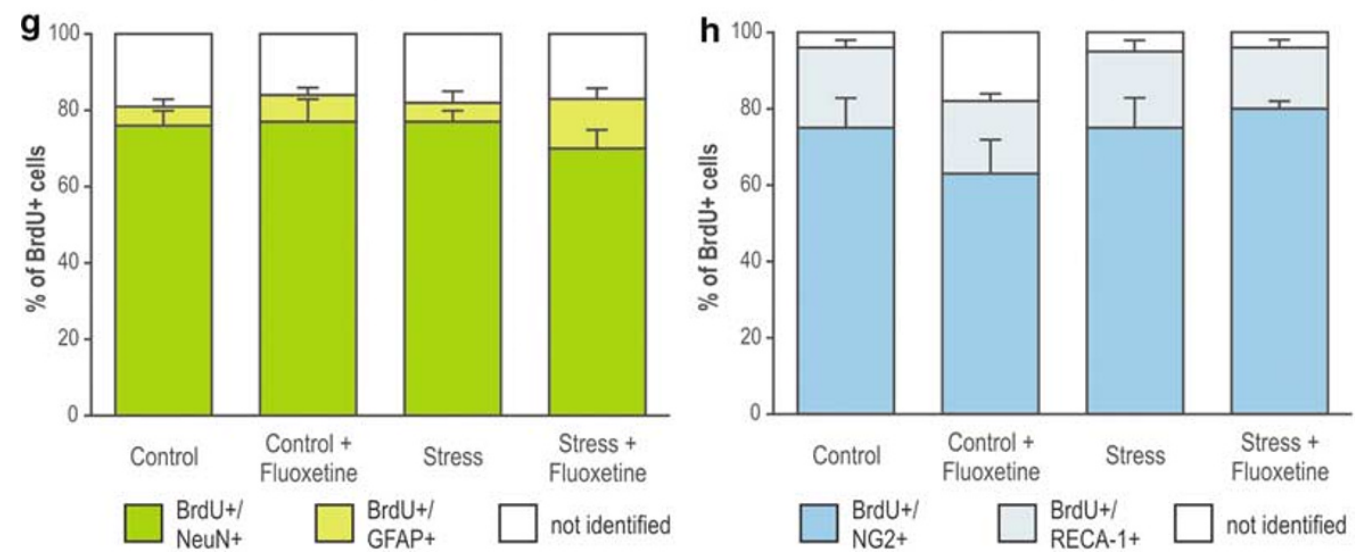

Figure 6 Representative examples of BrdU-labeled cells in the dentate gyrus (a) and in the PFC (b) from sections used for cell quantification. Dentate gyrus: phenotypic analysis with double-labeling revealed that majority of the newborn cells acquired neuronal phenotype (c and g). Representative examples of colocalization of BrdU positivity with the neuronal marker NeuN (c) and the astrocytic marker GFAP (d). PFC: We found no evidence of neurogenesis in the mPFC, instead the newly generated cells differentiated mainly into NG2-positive glia and to a minor portion into endothelial cells (e, f and h). Examples of double labeling of BrdU-positive cells with the glial marker NG2, a marker for synantocytes and oligodendrocyte precursor cells (e) and double labeling of BrdU-positive cells with the endothelial cell marker RECA-I (f). Scale bar: $100 \mu \mathrm{m}$ ( $a$ and b), $10 \mu \mathrm{m}$ ( $c-f$ ), and in insets of a and b. 

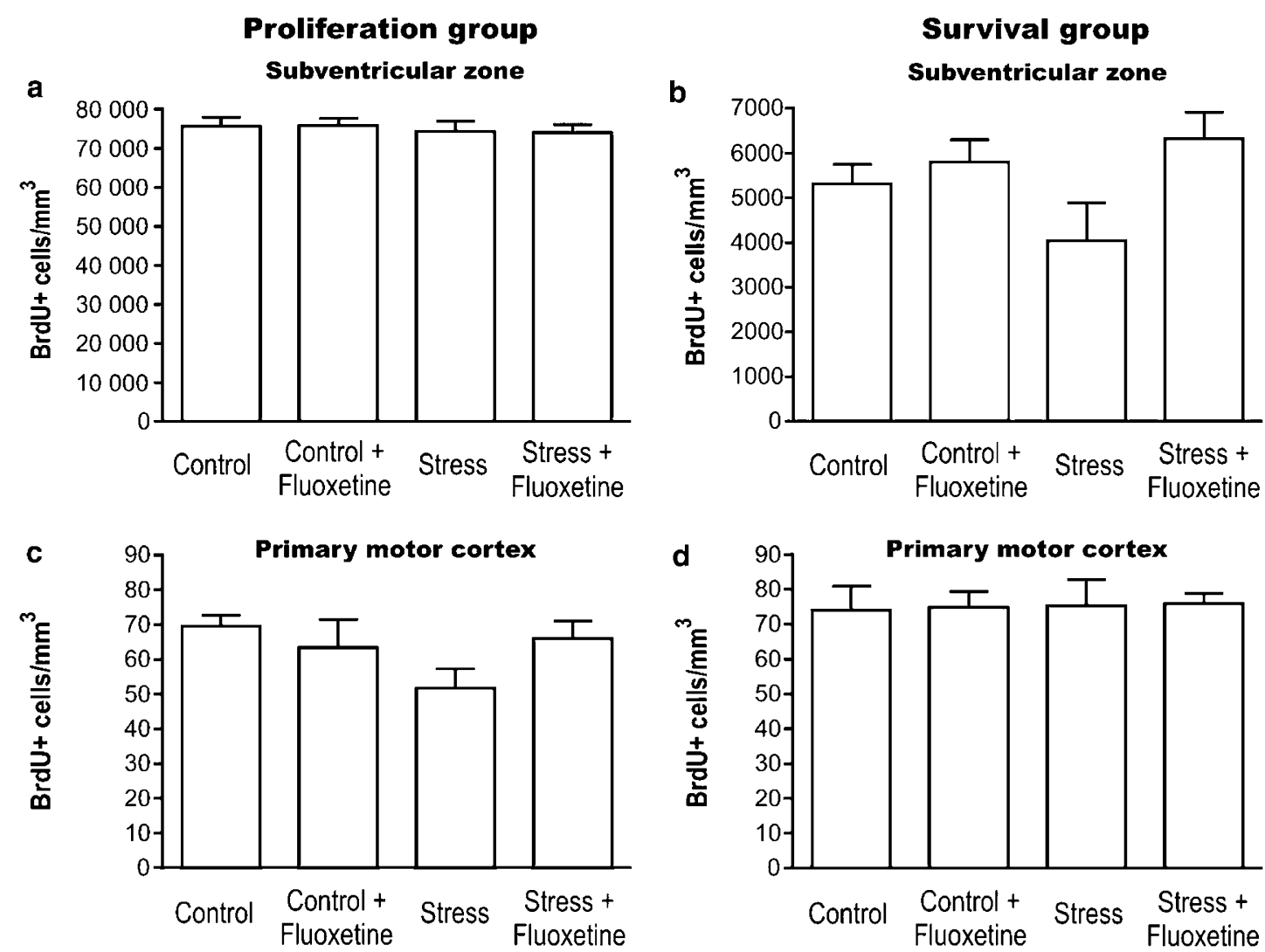

Figure 7 Effects of chronic psychosocial stress and concomitant fluoxetine treatment on cell proliferative activity (a and c) and survival of newborn cells (b and d) in nonlimbic structures, such as the subventricular zone/rostral migratory stream and primary motor cortex. Neither stress, nor fluoxetine treatment had a statistically significant effect on cytogenesis in these regions, except in the subventricular zone/rostral migratory stream of the survival group (b) yielding a significant main effect of drug treatment $(p<0.05)$. Furthermore, chronic stress suppressed cell proliferation in the primary motor cortex by $-26 \%$, but this effect was statistically not significant. Results are given as density of BrdU-positive cells $/ \mathrm{mm}^{3}$ area of interest (mean \pm SEM). Statistics: two-way ANOVA (stress $\times$ drug).

\section{In Nonlimbic Areas Cytogenesis is Mildly Affected by} Stress or Fluoxetine Treatment

We quantified the number of newly generated cells in two other reference areas in addition to the dentate gyrus and mPFC. The primary motor cortex and subventricular zone/ rostral migratory stream were examined to determine whether stress and/or fluoxetine treatment on cytogenesis is specific to limbic areas. As shown in Figure 7, neither stress nor fluoxetine treatment had a statistically significant effect on the proliferative activity, nor on the survival rate of the newly generated cells in these areas. The only exception was in the subventricular zone of the survival group where there was a significant main effect of drug treatment $\left(\mathrm{F}_{(3,20)}=4.69, p<0.05\right)$. However, because of the large variations between animals, post hoc analysis showed no significant differences between any groups. Chronic stress inhibited cell proliferation in the primary motor cortex with a nonsignificant reduction of $26 \%$.

\section{DISCUSSION}

This study has three novel findings. First, we have demonstrated that chronic stress not only inhibits adult neurogenesis in the dentate gyrus, but also suppresses cytogenesis in the mPFC. Second, we demonstrated that this inhibitory stress effect was blocked in both structures by treatment with the established antidepressant drug fluoxetine. The effects of stress and antidepressant treatment appear to be more pronounced in limbic structures, as cell proliferation in nonlimbic areas, such as the primary motor cortex and subventricular zone, was only mildly affected by these treatments. Third, we believe that this is the first report showing intrinsic hemispheric asymmetry in the rate of cytogenesis in the adult mPFC. Both the proliferative activity and the survival rate of the newborn cells in control animals were always higher in the left mPFC. Chronic stress had a greater suppressive effect in the left mPFC, resulting in a reversed hemispheric asymmetry. It is interesting that fluoxetine treatment abolished hemispheric differences both in control and stressed animals.

\section{Stress-Induced Structural Changes and Their Potential Implications for Psychiatry}

There is compelling experimental evidence, including the present data, that stress-induced reduction of dentate neurogenesis can be reversed by various types of antidepressant treatment (Dranovsky and Hen, 2006; WarnerSchmidt and Duman, 2006). These findings have excited researchers who have extensively examined the concept that altered cytogenesis and neurogenesis may contribute to the 
pathogenesis of depression (Santarelli et al, 2003; Duman, 2004), whereas others vigorously dispute this idea (Henn and Vollmayr, 2004). Clearly, the most direct approach to test this theory is the examination of dentate neurogenesis in depressed patients. So far, there is only one study published recently by Reif et al (2006), which compared the level of neural stem cell proliferation in post mortem hippocampal samples from patients with major depression, bipolar affective disorder and schizophrenia. The authors did not find any evidence of suppressed neurogenesis in the dentate gyri of depressed patients. Furthermore, antidepressant treatment did not result in an increase of neural stem cell proliferation. Unexpectedly, significantly reduced numbers of newly formed cells were found only in schizophrenic patients. Although this study was based on a relatively small sample size, and further studies are warranted, so far there is no clear clinical evidence that altered rate of adult dentate neurogenesis is critical to the etiopathology of affective disorders.

Parallel to the findings in the dentate gyrus, the PFC is now receiving increasing attention in preclinical research, especially because the involvement of this brain region in mood disorders is well documented (Drevets, 2000). Recent animal experiments show that chronic stress results in altered dendritic morphology, and reduced spine density in the $\mathrm{mPFC}$, as has been shown in the hippocampal CA3 region (Cook and Wellman, 2004; Radley et al, 2004, 2006). Treatment with the synthetic glucocorticoid dexamethasone results in neuronal loss and atrophy in the mPFC as well as in the granule cell layer of the dentate gyrus (Cerqueira et al, 2005). In the present study, we extend these findings, and report that chronic social defeat stress can suppress cytogenesis in the mPFC. As stress is associated with the risk of developing depression (Kessler, 1997; Kendler et al, 1999), the morphological findings of preclinical studies, where animals are exposed to chronic stressful experiences, are commonly related to the structural changes reported in the brains of depressed patients. In vivo imaging studies reveal selective volume reduction in the PFC (Drevets, 2000 ), and post mortem histological data show reductions in neuronal size and glial cell numbers in specific subregions of the frontal cortex in depressed patients (Öngür et al, 1998; Rajkowska et al, 1999; Cotter et al, 2001a, 2002; Uranova et al, 2004). It is tempting to speculate that our finding on the pronounced changes in gliogenesis after chronic stress exposure may relate to the abnormalities of glial cell numbers reported in the frontolimbic areas of depressed patients. Human studies focusing on gliogenis in the PFC of depressed patients may confirm or reject this hypothesis.

\section{Hemispheric Asymmetry}

Hemispheric specialization in the human brain is well known, and numerous studies document similar lateralized brain function in other mammals including rodents (eg, Sullivan and Gratton, 2002; Sullivan, 2004). Functional asymmetry in the human PFC exists not only in normal conditions, but altered hemispheric lateralization has also been demonstrated in various psychopathological conditions (Bench et al, 1992; Davidson, 1992). Current brain models of emotional processing hypothesize that positive (or approach-related) emotions are lateralized towards the left hemisphere, whereas negative (or withdrawal-related) emotions are lateralized towards the right hemisphere (Rotenberg, 2004). Some regard this as oversimplified, but many investigations have shown that damage of the left hemisphere is usually accompanied with depressed mood, whereas right hemispheric damage is associated with euphoric reactions (eg, Starkstein and Robinson, 1988; Rotenberg, 2004; Shenal et al, 2003).

The functional significance of the intrinsic lateralization of adult cytogenesis in the mPFC is unknown, but it is tempting to relate this finding to the clinical observations on lateralized emotional processing. We propose that the lateralization of cell proliferation in the mPFC might be a reflection of functional asymmetry. We found that the occurrence of cytogenesis is normally higher in the left PFC, which may be an indication of the left 'dominance' of this region in normal animals. Chronic stress had a greater suppressive effect on cytogenesis in the left PFC, resulting in a reversed asymmetry. Higher levels of cytogenesis in the right hemisphere in stressed animals may reflect hyperactivation of this area during stress. This presumption is based on clinical and preclinical findings. For example, electroencephalographic (EEG) studies in humans relate decreased left hemisphere activation to depressive conditions, and the association of hyperfunction in the right hemisphere with anxiety disorders (Sullivan and Gratton, 2002; Shenal et al, 2003). Depressed mood has also been associated with hypometabolism and volumetric reduction of the left PFC (Drevets et al, 1997; Drevets, 2000). Parallel to the human studies, a number of animal experiments have shown functional lateralization of the mPFC in stressful or highly emotional situations (Sullivan and Gratton, 2002). EEG studies of nonhuman primates found that animals with extreme right frontal activity had significantly elevated levels of plasma cortisol, and these animals displayed highly fearful behavior, suggesting that right frontal activity is a trait of a stressed or anxious individual (Kalin et al, 1998). Studies in rodents provide further evidence that the right PFC is directly linked to stress-regulatory systems (eg, Sullivan and Gratton, 1999, 2002; Sullivan, 2004). These observations are consistent with our results showing that the rate of cytogenesis was always higher in the left mPFC of control animals, but chronic stress inverted this asymmetry, with significantly more newborn cells in the right $\mathrm{mPFC}$.

We have shown that fluoxetine treatment abolished hemispheric differences in control and stressed animals, except in the Survival group of the Stress + Fluoxetinetreated animals in which the normally higher rate of newborn cell survival in the left mPFC was restored (Figure 5b). The survival rate of the newly generated cells in these animals was $23 \%$ higher in the left mPFC than in the right $\mathrm{mPFC}$. This ratio was very similar to the values of the Control group $(+18 \%$ left $v s$ right $)$, but the paired $t$-test did not show significant differences because of individual variability. An experiment with a larger sample size may show a statistically significant restoration of hemispheric asymmetry after antidepressant treatment in the incidence of cytogenesis in the mPFC. This may be important to determine because normalization of hemispheric imbalances of prefrontal function in stress-related 
psychopathology has been related to the effectiveness of therapeutic interventions (Pascual-Leone et al, 1996).

\section{Phenotypic Analysis of the Newborn Cells}

Most of the newly generated cells (70-80\%) in the dentate gyrus differentiated into neurons, as shown by double labeling with the neuronal marker NeuN. A much smaller number of cells (about 10\%) expressed the astroglial marker GFAP. The remaining 20\% were not labeled with either cell markers, and these cells may represent another phenotype or they may be quiescent, undifferentiated cells. In agreement with earlier studies, this neuron-to-glia ratio was not significantly influenced by the various treatments (Czéh et al, 2002; Malberg et al, 2000).

Spontaneous neurogenesis in the adult neocortex is a controversial issue. The presence of newborn neurons has been reported in various neocortical areas of adult nonhuman primates (Gould et al, 1999, 2001; Bernier et al, 2002), but these findings have not been replicated by other investigators (Kornack and Rakic, 2001). Interestingly, a recent study came to the conclusion that GABAergic interneurons are generated in the neocortex of adult rats (Dayer et al, 2005).

In the present study, our principal aim was to identify the major phenotype of the newly generated cells in the mPFC. In our case, most of the newly generated cells differentiated into NG2-positive glia, with a few differentiating into endothelial cells. We tested several other cellular markers, but the NG2 and RECA-1 phenotypic markers labeled the largest population of BrdU-positive cells in the mPFC. Similar findings were reported earlier by Kodama et al (2004) and Madsen et al (2005). In the present study, we could not observe any newborn cells in the neocortex that acquired a neuronal phenotype. Our failure to find any newborn neurons in the mPFC might be due to the fact that we employed a significantly different BrdU-labeling protocol compared with that of Dayer et al (2005), who injected much more BrdU and used longer survival times. A more systematic analysis using different BrdU-labeling protocols, survival times and various interneuronal markers may reveal that a small subset of the newly generated cells affected by stress and antidepressant treatment could be GABAergic neurons.

NG2-positive cells comprise an abundant glial cell population that is widely and uniformly distributed throughout the mature CNS (Butt et al, 2002, 2005). However, the exact classification and functional role of this glial type is not completely understood. Traditionally, NG2expressing glia were considered to be oligodendrocyte precursor cells that persist in the adult CNS, generating oligodendrocytes throughout life (Butt et al, 2002, 2005). However, these cells have many of the morphological features of astrocytes. They are stellate cells with elaborate multiple branching processes that form multiple contacts with neurons, astrocytes, oligodendrocytes, and myelin (Butt et al, 2002, 2005). NG2-positive synantocytes (also known as polydendrocytes) may be specialized to monitor signals from neurons and glia, and to respond to changes in the integrity of the CNS (Butt et al, 2002, 2005). Recent studies have shown that glucocorticoid treatment inhibits NG2-positive cell proliferation in the adult rat hippocampus
(Alonso, 2000; Wennström et al, 2006), whereas electroconvulsive seizure treatment reverses this effect (Wennström et al, 2006). The functional significance of these observations is not clear, but recent theories suggest that glial cell dysfunction may contribute to the pathogenesis of affective disorders (Coyle and Schwarcz, 2000; Cotter et al, 2001b). Moreover, there is experimental evidence indicating that stress and antidepressant treatment can induce changes in structural plasticity of astrocytes and NG2-positive glia (Czéh et al, 2006; Wennström et al, 2006). The majority of the post mortem histopathological studies on glial reduction in frontolimbic structures have not identified which populations of glial cells are reduced, but there is an indication of the involvement of both astrocytes and oligodendrocytes (Cotter et al, 2001b; Rajkowska, 2003).

The proliferation of endothelial cells in the $\mathrm{mPFC}$ was affected by the chronic social defeat stress and fluoxetine treatment in opposite ways. This observation agrees with recent reports showing that fluoxetine or ECS treatment can stimulate the genesis of endothelial cells in both the hippocampus and the mPFC (Hellsten et al, 2004; Kodama et al, 2004; Madsen et al, 2005). Furthermore, this ECSinduced increase in endothelial cell proliferation is accompanied by increased angiogenesis in the hippocampus (Hellsten et al, 2005; Newton et al, 2006). The functional significance of these changes is not known, but they may be related to the 'vascular depression' hypothesis, which suggests that cerebrovascular disease may predispose, precipitate, or perpetuate at least some depressive syndromes, especially in geriatric patients (Alexopoulos et al, 1997).

\section{CONCLUSION}

We demonstrate that chronic stress can specifically inhibit both neuro- and gliogenesis in limbic structures, such as the hippocampal formation and PFC. Both of these structures are crucial to affect regulation and mediation of stress responses. We also showed that the suppressive effect of stress was blocked by treatment with the antidepressant drug fluoxetine. Finally, we found that the occurrence of cytogenesis is normally higher in the left PFC. The latter finding may be an indication of the left 'dominance' of this region in normal animals. Chronic stress had a greater suppressive effect on cytogenesis in the left PFC, resulting in reversed asymmetry. Higher levels of cytogenesis in the right hemisphere in stressed animals may reflect hyperactivation of this area during stress. These cellular changes may contribute to the structural and functional abnormalities reported in the frontal cortical areas of depressed patients.

\section{ACKNOWLEDGEMENTS}

This study was partially supported by GlaxoSmithKline, Verona, Italy. We thank S Donath, S Lüert, S Bauch and S Barsky for their excellent technical assistance.

\section{REFERENCES}

Alexopoulos GS, Meyers BS, Young RC, Campbell S, Silbersweig D, Charlson M (1997). 'Vascular depression' hypothesis. Arch Gen Psychiatry 54: 915-922. 
Alonso G (2000). Prolonged corticosterone treatment of adult rats inhibits the proliferation of oligodendrocyte progenitors present throughout white and gray matter regions of the brain. Glia 31: 219-231.

Baumann P, Hiemke C, Ulrich S, Eckermann G, Gaertner I, Gerlach $M$ et al (2004). The AGNP-TDM expert group consensus guidelines: therapeutic drug monitoring in psychiatry. Pharmacopsychiatry 37: 243-265.

Bench CJ, Friston KJ, Brown RG, Scott LC, Frackowiak RS, Dolan RJ (1992). The anatomy of melancholia-focal abnormalities of cerebral blood flow in major depression. Psychol Med 22: 607-615.

Bernier PJ, Bedard A, Vinet J, Levesque M, Parent A (2002). Newly generated neurons in the amygdala and adjoining cortex of adult primates. Proc Natl Acad Sci USA 99: 11464-11469.

Butt AM, Hamilton N, Hubbard P, Pugh M, Ibrahim M (2005). Synantocytes: the fifth element. J Anat 207: 695-706.

Butt AM, Kiff J, Hubbard P, Berry M (2002). Synantocytes: new functions for novel NG2 expressing glia. J Neurocytol 31: 551-565.

Cerqueira JJ, Pego JM, Taipa R, Bessa JM, Almeida OF, Sousa N (2005). Morphological correlates of corticosteroid-induced changes in prefrontal cortex-dependent behaviors. J Neurosi 25: 7792-7800.

Cook SC, Wellman CL (2004). Chronic stress alters dendritic morphology in rat medial prefrontal cortex. J Neurobiol 60: 236-248.

Cotter D, Mackay D, Chana G, Beasley C, Landau S, Everall IP (2002). Reduced neuronal size and glial cell density in area 9 of the dorsolateral prefrontal cortex in subjects with major depressive disorder. Cereb Cortex 12: 386-394.

Cotter D, Mackay D, Landau S, Kerwin R, Everall I (2001a). Reduced glial cell density and neuronal size in the anterior cingulate cortex in major depressive disorder. Arch Gen Psychiatry 58: 545-553.

Cotter DR, Pariante CM, Everall IP (2001b). Glial cell abnormalities in major psychiatric disorders: the evidence and implications. Brain Res Bull 55: 585-595.

Coyle JT, Schwarcz R (2000). Mind glue: implications of glial cell biology for psychiatry. Arch Gen Psychiatry 57: 90-93.

Czéh B, Michaelis T, Watanabe T, Frahm J, de Biurrun G, van Kampen $\mathrm{M}$ et al (2001). Stress-induced changes in cerebral metabolites, hippocampal volume, and cell proliferation are prevented by antidepressant treatment with tianeptine. Proc Natl Acad Sci USA 98: 12796-12801.

Czéh B, Simon M, Schmelting B, Hiemke C, Fuchs E (2006). Astroglial plasticity in the hippocampus is affected by chronic psychosocial stress and concomitant fluoxetine treatment. Neuropsychopharmacology 31: 1616-1626.

Czéh B, Welt T, Fischer AK, Erhardt A, Schmitt W, Müller MB et al (2002). Chronic psychosocial stress and concomitant repetitive transcranial magnetic stimulation: effects on stress hormone levels and adult hippocampal neurogenesis. Biol Psychiatry 52: 1057-1065.

D'Sa C, Duman RS (2002). Antidepressants and neuroplasticity. Bipolar Disord 4: 183-194.

Davidson RJ (1992). Anterior cerebral asymmetry and the nature of emotion. Brain Cogn 20: 125-151.

Dayer AG, Cleaver KM, Abouantoun T, Cameron HA (2005). New GABAergic interneurons in the adult neocortex and striatum are generated from different precursors. J Cell Biol 168: 415-427.

Dranovsky A, Hen R (2006). Hippocampal neurogenesis: regulation by stress and antidepressants. Biol Psychiatry 59: $1136-1143$.

Drevets WC (2000). Functional anatomical abnormalities in limbic and prefrontal cortical structures in major depression. Prog Brain Res 126: 413-431.
Drevets WC, Price JL, Simpson Jr JR, Todd RD, Reich T, Vannier $M$ et al (1997). Subgenual prefrontal cortex abnormalities in mood disorders. Nature 386: 824-827.

Duijvestijn AM, van Goor H, Klatter F, Majoor GD, van Bussel E, van Breda Vriesman PJ (1992). Antibodies defining rat endothelial cells: RECA-1, a pan-endothelial cell-specific monoclonal antibody. Lab Invest 66: 459-466.

Duman RS (2004). Depression: a case of neuronal life and death? Biol Psychiatry 56: 140-145.

Gould E, Reeves AJ, Graziano MS, Gross CG (1999). Neurogenesis in the neocortex of adult primates. Science 286: 548-552.

Gould E, Vail N, Wagers M, Gross CG (2001). Adult-generated hippocampal and neocortical neurons in macaques have a transient existence. Proc Natl Acad Sci USA 98: 10910-10917.

Gundersen HJ, Bagger P, Bendtsen TF, Evans SM, Korbo L, Marcussen $\mathrm{N}$ et al (1988). The new stereological tools: disector, fractionator, nucleator and point sampled intercepts and their use in pathological research and diagnosis. APMIS 96: 857-881.

Hellsten J, Wennstrom M, Bengzon J, Mohapel P, Tingström A (2004). Electroconvulsive seizures induce endothelial cell proliferation in adult rat hippocampus. Biol Psychiatry 55: 420-427.

Hellsten J, West MJ, Arvidsson A, Ekstrand J, Jansson L, Wennstrom $\mathrm{M}$ et al (2005). Electroconvulsive seizures induce angiogenesis in adult rat hippocampus. Biol Psychiatry 58: 871-878.

Henn FA, Vollmayr B (2004). Neurogenesis and depression: etiology or epiphenomenon? Biol Psychiatry 56: 146-150.

Kalin NH, Larson C, Shelton SE, Davidson RJ (1998). Asymmetric frontal brain activity, cortisol, and behavior associated with fearful temperament in rhesus monkeys. Behav Neurosci 112: 286-292.

Kendler KS, Karkowski LM, Prescott CA (1999). Causal relationship between stressful life events and the onset of major depression. Am J Psychiatry 156: 837-841.

Kessler RC (1997). The effects of stressful life events on depression. Annu Rev Psychol 48: 191-214.

Keuker JIH, Vollmann-Honsdorf GK, Fuchs E (2001). How to use the optical fractionator: an example based on the estimation of neurons in the hippocampal CA1 and CA3 regions of tree shrews. Brain Res Brain Res Protoc 7: 211-221.

Kodama M, Fujioka T, Duman RS (2004). Chronic olanzapine or fluoxetine administration increases cell proliferation in hippocampus and prefrontal cortex of adult rat. Biol Psychiatry 56: 570-580.

Koolhaas JM, De Boer SF, De Rutter AJ, Meerlo P, Sgoifo A (1997). Social stress in rats and mice. Acta Physiol Scand 640: 69-72.

Kornack DR, Rakic P (2001). Cell proliferation without neurogenesis in adult primate neocortex. Science 294: 2127-2130.

Lledo PM, Alonso M, Grubb MS (2006). Adult neurogenesis and functional plasticity in neuronal circuits. Nat Rev Neurosci 7: 179-193.

Madsen TM, Yeh DD, Valentine GW, Duman RS (2005). Electroconvulsive seizure treatment increases cell proliferation in rat frontal cortex. Neuropsychopharmacology 30: 27-34.

Malberg JE, Eisch AJ, Nestler EJ, Duman RS (2000). Chronic antidepressant treatment increases neurogenesis in adult rat hippocampus. J Neurosci 20: 9104-9110.

Manji HK, Drevets WC, Charney DS (2001). The cellular neurobiology of depression. Nat Med 7: 541-547.

McEwen BS (2000). The neurobiology of stress: from serendipity to clinical relevance. Brain Res 886: 172-189.

Miczek KA (1991). Tolerance to the analgesic, but not discriminative stimulus effects of morphine after brief social defeat in rats. Psychopharmacology (Berlin) 104: 181-186.

Muscat R, Willner P (1992). Suppression of sucrose drinking by chronic mild unpredictable stress: a methodological analysis. Neurosci Biobehav Rev 16: 507-517. 
Newton SS, Girgenti MJ, Collier EF, Duman RS (2006). Electroconvulsive seizure increases adult hippocampal angiogenesis in rats. Eur J Neurosci 24: 819-828.

Öngür D, Drevets WC, Price JL (1998). Glial reduction in the subgenual prefrontal cortex in mood disorders. Proc Natl Acad Sci USA 95: 13290-13295.

Pascual-Leone A, Rubio B, Pallardo F, Catala MD (1996). Rapidrate transcranial magnetic stimulation of left dorsolateral prefrontal cortex in drug-resistant depression. Lancet 348: 233-237.

Paxinos G, Watson C (1986). The Rat Brain in Stereotaxic Coordinates. Academic Press: New York.

Radley JJ, Morrison JH (2005). Repeated stress and structural plasticity in the brain. Ageing Res Rev 4: 271-287.

Radley JJ, Rocher AB, Janssen WG, Hof PR, McEwen BS, Morrison $\mathrm{JH}$ (2005). Reversibility of apical dendritic retraction in the rat medial prefrontal cortex following repeated stress. Exp Neurol 196: 199-203.

Radley JJ, Rocher AB, Miller M, Janssen WG, Liston C, Hof PR et al (2006). Repeated stress induces dendritic spine loss in the rat medial prefrontal cortex. Cereb Cortex 16: 313-320.

Radley JJ, Sisti HM, Hao J, Rocher AB, McCall T, Hof PR et al (2004). Chronic behavioral stress induces apical dendritic reorganization in pyramidal neurons of the medial prefrontal cortex. Neuroscience 125: 1-6.

Rajkowska G (2003). Depression: what we can learn from postmortem studies. Neuroscientist 9: 273-284.

Rajkowska G, Miguel-Hidalgo JJ, Wei J, Dilley G, Pittman SD, Meltzer HY et al (1999). Morphometric evidence for neuronal and glial prefrontal cell pathology in major depression. Biol Psychiatry 45: 1085-1098.

Reif A, Fritzen S, Finger M, Strobel A, Lauer M, Schmitt A et al (2006). Neural stem cell proliferation is decreased in schizophrenia, but not in depression. Mol Psychiatry 11: 514-522.

Rotenberg VS (2004). The peculiarity of the right-hemisphere function in depression: solving the paradoxes. Prog Neuropsychopharmacol Biol Psychiatry 28: 1-13.

Rygula R, Abumaria N, Domenici E, Hiemke C, Fuchs E (2006b). Effects of fluoxetine on behavioral deficits evoked by chronic social stress in rats. Behav Brain Res 174: 188-192.

Rygula R, Abumaria N, Flügge G, Fuchs E, Rüther E, HavemannReinecke U (2005). Anhedonia and motivational deficits in rats: impact of chronic social stress. Behav Brain Res 162: 127-134.

Rygula R, Abumaria N, Flügge G, Hiemke C, Fuchs E, Rüther E et al (2006a). Citalopram counteracts depressive-like symptoms evoked by chronic social stress in rats. Behav Pharmacol 17: 19-29.
Sachse J, Hartter S, Weigmann H, Hiemke C (2003). Automated determination of amisulpride by liquid chromatography with column switching and spectrophotometric detection. J Chromatogr B Analyt Technol Biomed Life Sci 784: 405-410.

Santarelli L, Saxe M, Gross C, Surget A, Battaglia F, Dulawa S et al (2003). Requirement of hippocampal neurogenesis for the behavioral effects of antidepressants. Science 301: 805-809.

Sapolsky RM, Romero LM, Munck AU (2000). How do glucocorticoids influence stress responses? Integrating permissive, suppressive, stimulatory, and preparative actions. Endocr Rev 21: 55-89.

Shenal BV, Harrison DW, Demaree HA (2003). The neuropsychology of depression: a literature review and preliminary model. Neuropsychol Rev 13: 33-42.

Starkstein SE, Robinson RG (1988). Lateralized emotional response following stroke. In: Kinsbourne M (ed). Cerebral Hemisphere Function in Depression. American Psychiatric Press: Washington, DC. pp 25-47.

Sullivan RM (2004). Hemispheric asymmetry in stress processing in rat prefrontal cortex and the role of mesocortical dopamine. Stress 7: 131-143.

Sullivan RM, Gratton A (1999). Lateralized effects of medial prefrontal cortex lesions on neuroendocrine and autonomic stress responses in rats. J Neurosci 19: 2834-2840.

Sullivan RM, Gratton A (2002). Prefrontal cortical regulation of hypothalamic-pituitary-adrenal function in the rat and implications for psychopathology: side matters. Psychoneuroendocrinology 27: 99-114.

Uranova NA, Vostrikov VM, Orlovskaya DD, Rachmanova VI (2004). Oligodendroglial density in the prefrontal cortex in schizophrenia and mood disorders: a study from the Stanley Neuropathology Consortium. Schizophr Res 67: 269-275.

Vyas A, Mitra R, Shankaranarayana Rao BS, Chattarji S (2002). Chronic stress induces contrasting patterns of dendritic remodeling in hippocampal and amygdaloid neurons. J Neurosci 22: 6810-6818.

Warner-Schmidt JL, Duman RS (2006). Hippocampal neurogenesis: opposing effects of stress and antidepressant treatment. Hippocampus 16: 239-249.

Wennström M, Hellsten J, Ekstrand J, Lindgren H, Tingström A (2006). Corticosterone-induced inhibition of gliogenesis in rat hippocampus is counteracted by electroconvulsive seizures. Biol Psychiatry 59: 178-186.

West MJ (1999). Stereological methods for estimating the total number of neurons and synapses: issues of precision and bias. Trends Neurosci 22: 51-61. 